\title{
Utility of Cytology Microarray Constructed From Effusion Cell Blocks for Immunomarker Validation
}

\author{
Robert T. Pu, MD, PhD \\ Thomas J. Giordano, MD, PhD \\ Claire W. Michael, MD
}

Department of Pathology, University of Michigan, Ann Arbor, Michigan.
Address for reprints: Robert T. Pu, MD, PhD, Department of Pathology, University of Michigan, 1500 East Medical Center Drive, Ann Arbor, MI 48109-0054; Fax: (734) 763-4095; E-mail: robertpu@ umich.edu

Received April 26, 2008; revision received June 16, 2008; accepted June 19, 2008.
BACKGROUND. Tissue microarray allows rapid and efficient evaluation of gene expression at the protein level and of immunochemical markers. To our knowledge, there has been no report of constructing cytology microarray using effusion cell blocks and testing its utility in immunochemical marker validation.

METHODS. A total of 23 malignant effusions (primary tumor of breast [5], GI tract [5], lung [5] and ovary [8]) were used to construct a cytology microarray so that 3 cores of $0.6 \mathrm{~mm}$ in diameter were taken from the original cell blocks. Antibodies including AE1/AE3, EMA, and Ki-67 were applied to all cases, and CK7, CK20, TTF-1, WT-1, ER, and PR antibodies were used for selected cases. The cellularity, composition of cells, the staining pattern, and the intensity of each antibody were compared between corresponding cell block sections and CMA cores.

RESULTS. The composition of tumor cells in the original block and the cores (including Sections 1 and 45) on cytology microarray were similar, ranging from $5 \%$ to $90 \%$. Immunostains of AE1/AE3 and EMA were all positive and $100 \%$ concordant between the originals and cytology microarray. Similarly, CK7, CK20, ER, PR, TTF-1, and WT-1 stained both original blocks and cytology microarray with a high level of agreement with respect to percentage of positive cells, staining pattern (cytoplasm or nuclear), and intensity. Ki-67 stain showed slightly lower concordance $(84 \%)$ with a few cases not in agreement because of low tumor burden in the original block coupled with low percentage of staining by antibody.

CONCLUSIONS. Three $0.6 \mathrm{~mm}$ cores of cytology microarray are representative of the original cell block with cellularity and antibody staining pattern, intensity, and percentage. Therefore, CMA has a great potential in clinical research and practice as it allows rapid validation of immunocytochemical markers. Cancer (Cancer Cytopathol) 2008;114:300-6. ㄷ 2008 American Cancer Society.

KEYWORDS: cytology microarray, malignant effusions, antibodies, tumor cells.

A lthough tissue microarrays (TMA) have been widely used in the cancer research field for high-throughput gene expression analysis and validation of tumor markers on tissue, ${ }^{1-8}$ cytology microarray (CMA) has not been tested in cytology samples for such a purpose. In particular, the use of CMA for the purpose of marker validation or other research has not been reported. There is 1 recent report using cytology material to construct microarray with success but no marker testing was performed in that study. ${ }^{9}$ Cytology material is usually presented in the form of small cellular aggregates rather than the large tissue fragments seen in surgical pathology material. Whether the small cell clusters in cores of CMA will be representative of the standard section is not known. The objectives of this study are to first validate the utility of CMA in its representation of the original cell blocks in cell numbers and composition; and then to confirm that immunostains on CMA can recapitulate the original section with 
TABLE 1

Lists of Antibody and Dilutions

\begin{tabular}{|c|c|c|c|c|c|c|c|c|c|}
\hline & AE1/AE3 & EMA & Ki67 & CK7 & CK20 & ER & PR & TTF-1 & WT-1 \\
\hline Vendor & Chemicon & DAKO & DAKO & DAKO & DAKO & DAKO & DAKO & DAKO & Cell Marque Corp \\
\hline Cat\# & MAB 3412 & M0613 & M7241-01 & M7018 & M7019 & M7047 & M3569 & M3575-01 80703/1 & CMC788 \\
\hline Clone & - & E29 & MIB-1 & OV-TL 12/10 & Ks20.8 & 1D5 & PgR 636 & - & 6F-H2 \\
\hline Dilution & 1:100 & $1: 25$ & 1:50 & 1:12.5 & $1: 25$ & 1:50 & 1:50 & 1:200 & $1: 30$ \\
\hline
\end{tabular}

AE1/AE3 indicates cytokeratin.

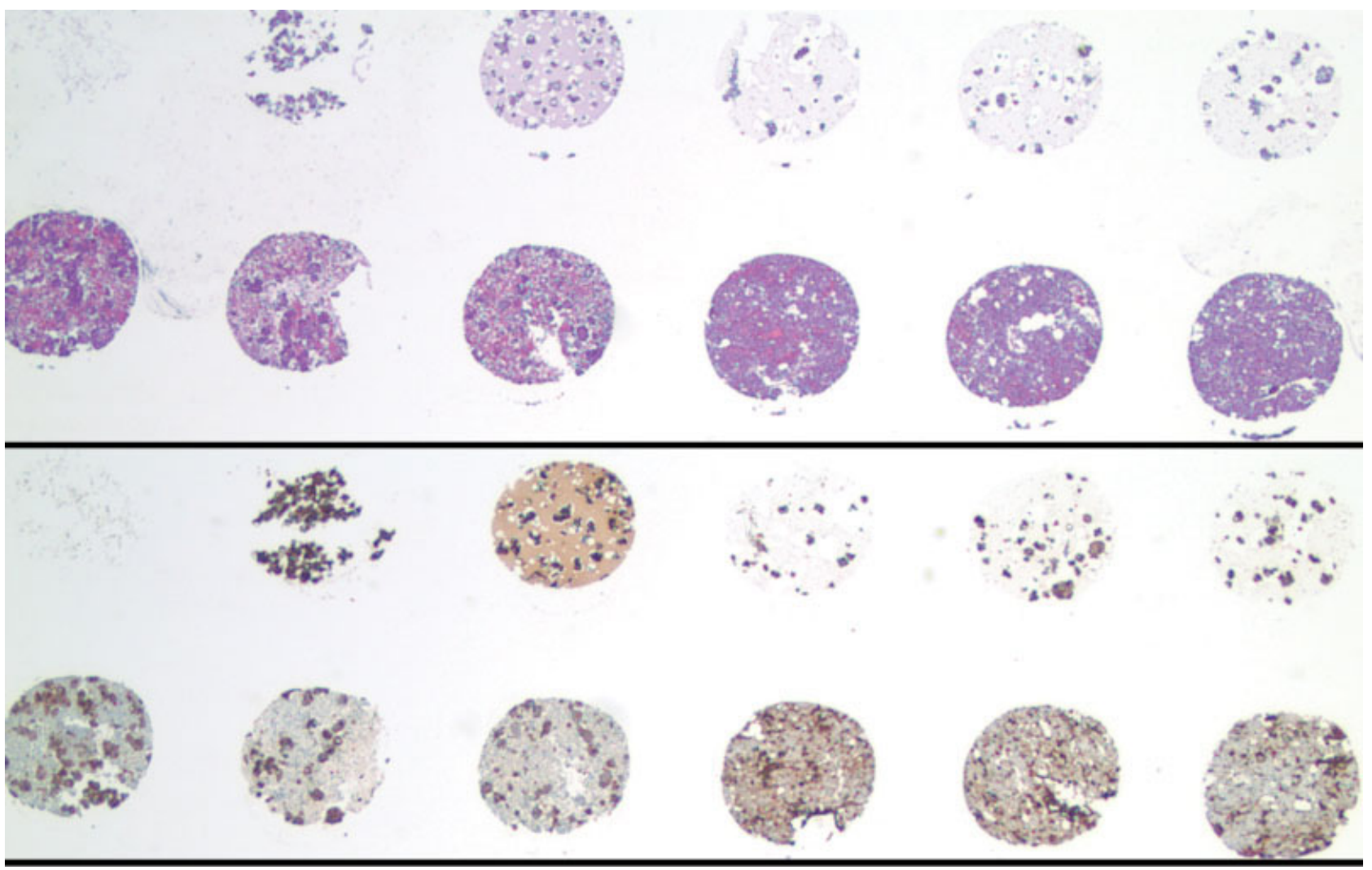

FIGURE 1. Representative CMA cores stained with hematoxylin and eosin (top 2 rows) or immunostained by AE1/AE3 antibody (bottom 2 rows). Four cases are represented with triplet cores (from right to left), representing cases with low (1 core of the first case had no cells) to moderate cellularity and moderate to strong cytoplasmic stain by AE1/AE3.

several antibodies frequently used in differential diagnosis of some common tumors.

\section{MATERIALS AND METHODS}

The authors constructed a microarray using standard cell blocks obtained from malignant effusions. The original tumors were known and the subsequent effusions were diagnosed by evaluation of morphology and often supported with immunocytochemical stain profile and clinical outcomes. Fresh effusions were centrifuged and sediments were used to make cell blocks by plasma-thrombin method. Briefly, after decanting supernatant, several drops of plasma and thrombin were added to the sediments to mix by gentle vortex and the mixture was then allowed to clot, followed by fixation with $10 \%$ buffered formalin solution for at least 1 hour (up to 10 hours) before being processed for embedding in paraffin block. A total of 23 malignant effusions of primary tumor of breast, lung, ovary, and gastrointestinal (GI) tract (including esophageal and pancreatic carcinoma) were used to construct a CMA so that 3 cores, each $0.6 \mathrm{~mm}$ in diameter, were taken from each of the original effusion cell blocks. Three cores were taken 
TABLE 2

Comparison Between Original Cell Block and CMA for Tumor Cell, and Number of Cores Present at Different Levels

\begin{tabular}{|c|c|c|c|c|c|c|c|}
\hline \multirow[b]{2}{*}{ Case No. } & \multirow[b]{2}{*}{ Site } & \multicolumn{3}{|c|}{ \% Estimated Tumor Cells } & \multicolumn{3}{|c|}{${ }^{*}$ Cores on Deeper Sections } \\
\hline & & Original CB & $1^{\text {st }}$ CMA Section & $45^{\text {th }}$ Section & $\# 15$ & $\# 30$ & $\# 45$ \\
\hline 1 & Breast & 60 & 60 & 60 & & & \\
\hline 2 & Breast & 80 & 80 & 80 & & & \\
\hline 3 & Breast & 30 & 30 & 30 & & & \\
\hline 4 & Breast & 90 & 90 & 90 & & & \\
\hline 5 & Breast & 30 & 30 & 30 & & & \\
\hline 6 & Lung & $5-10$ & $5-10$ & $\leq 5$ & & & 2 \\
\hline 7 & Lung & 80 & 80 & 80 & & & \\
\hline 8 & Lung & $5-10$ & $5-10$ & $\leq 5$ & & & \\
\hline 9 & Lung & 90 & 90 & 90 & & & \\
\hline 10 & Lung & 90 & 90 & 90 & & & \\
\hline 11 & Ovary & 50 & 50 & 50 & & & \\
\hline 12 & Ovary & $5-10$ & $5-10$ & $\leq 5$ & & & 2 \\
\hline 13 & Ovary & 40 & 40 & 40 & & & \\
\hline 14 & Ovary & 70 & 70 & 70 & & & \\
\hline 15 & Ovary & 25 & 25 & 25 & & & \\
\hline 16 & Ovary & 40 & 40 & 40 & & & \\
\hline 17 & Ovary & 90 & 90 & 70 & 2 & 2 & 2 \\
\hline 18 & Ovary & 90 & 90 & 90 & & & \\
\hline 19 & GI tract & 10 & 10 & 10 & & & \\
\hline 20 & GI tract & 10 & $5-10$ & $\leq 5$ & & & \\
\hline 21 & GI tract & 20 & 20 & 20 & & & \\
\hline 22 & GI tract & 10 & 10 & 10 & & & \\
\hline 23 & GI tract & 15 & 15 & 0 & 2 & 0 & 0 \\
\hline
\end{tabular}

from areas representative of the original cell block by aligning with spots marked on cell block hematoxylin and eosin ( $\mathrm{H} \& \mathrm{E}$ ) slides selected by a cytopathologist (C. W. Michael). Normal tissue controls were also included in the CMA block. In total, 84 cores consisting of 5 types of control of tissues $(5 \times 3=15)$ and 23 malignant effusions $(23 \times 3=69)$ were included in constructing this CMA.

On hematoxylin and eosin (H \& E) stain, visual estimated percentage of tumor cells on 3 cores and original cell block sections were recorded and compared. The percentage of tumor cells in proportion to all cells on the core was estimated by visual observation of 10 randomly selected high power fields in the cell block from the vicinity where the cores were taken. For CMA, the estimated percentages of tumor cells in each case were averaged from 3 cores obtained by examination of all CMA cores at high power view $(200 \times$ magnification). However, in cases where there were only 1 or 2 cores left, the average numbers were obtained by dividing the total by 1 or 2 instead of 3. Commonly used antibodies (Table 1), staining cytoplasm (cytokeratin [CK] AE1/AE3, epithelial membrane antigen [EMA]), and nuclei (Ki-
67) were applied to all of the original cell block sections and CMA according to established protocol and conditions. Selected antibodies that are useful in differential diagnosis of each primary cancer were also included: estrogen receptor (ER), progesterone receptor (PR), CK7, CK20, for breast cancer; thyroid transcription factor-1 (TTF-1), CK7, CK20, for lung cancer; CK20, CK7 for GI tract cancer; and WT-1 for ovarian cancer (Table 1). Stain pattern and percentages of positively immunostained tumor cells on original cell block slides and on CMA were recorded for comparison. Cytoplasmic stain by AE1/AE3, CK7, and CK20 were considered positive patterns, whereas cytoplasmic and membranous stains for EMA and nuclear stain for Ki-67, ER, PR, TTF-1, and WT-1 were considered positive patterns. Stain intensity was recorded as negative $(-)$ or positive (weak, +1 ; moderate, +2 ; and strong, +3 ), and the percentage of tumor cells that were positive were also recorded.

\section{RESULTS}

A total of 23 tumor samples from effusions with primary tumor of breast (5), lung (5), ovary (8), and GI tract (5, including esophageal and pancreatic) were 


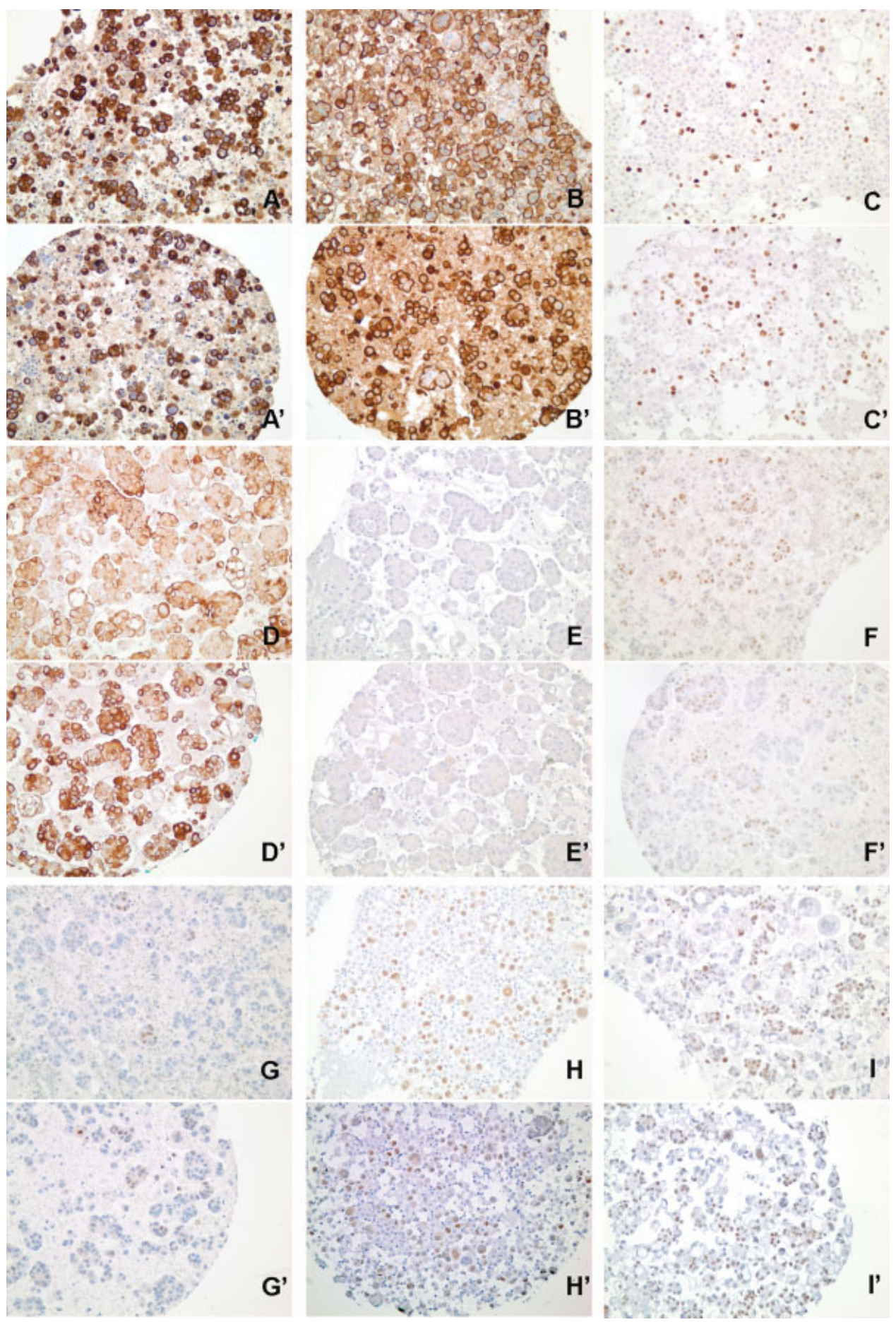

FIGURE 2. Representative images of each immunostain of cell blocks and their corresponding CMA cores are shown. Images labeled $A-I$ are from cell blocks, whereas the ones labeled $A^{\prime}-I^{\prime}$ are from CMA cores. A-A': AE1/AE3; B-B': EMA; C-C': Ki67; D-D': CK7; E-E':CK20; F-F': ER; G-G': PR; H-H': TTF-1; I-I': WT-1 (Original magnification, $\times 200$ ). 
TABLE 3

High Concordance Between CMA and Original Cell Block on Stains With 3 Antibodies Applied to All Samples

\begin{tabular}{|c|c|c|c|c|c|}
\hline \multirow[b]{2}{*}{ CMA } & \multicolumn{4}{|c|}{ Cell Block Sections } & \multirow[b]{2}{*}{ Agreement } \\
\hline & Negative & Weak & Moderate & Strong & \\
\hline \multicolumn{5}{|l|}{ AE1/AE3 } & $100 \% \dagger$ \\
\hline \multicolumn{6}{|l|}{ Negative } \\
\hline \multicolumn{6}{|l|}{ Weak } \\
\hline Moderate & & & $2 \dagger$ & & \\
\hline Strong & & & & $21 \dagger$ & \\
\hline \multicolumn{5}{|l|}{ EMA } & $100 \% \dagger$ \\
\hline Negative & & & $2^{*}$ & & \\
\hline \multicolumn{6}{|l|}{ Weak } \\
\hline Moderate & & & $2 \dagger$ & & \\
\hline Strong & & & & $19 \dagger$ & \\
\hline \multicolumn{5}{|l|}{ Ki-67 } & $84 \% \dagger$ \\
\hline Negative $(<5 \%)$ & & $2^{*}$ & $2^{*}$ & & \\
\hline Weak (5-15\%) & & $2 \dagger$ & 1 & & \\
\hline Moderate (15-30\%) & & & $3 \dagger$ & 2 & \\
\hline Strong $(>30 \%)$ & & & & $11 \dagger$ & \\
\hline
\end{tabular}

CMA indicates cytology microarray; AE1/AE3, cytokeratin; EMA, epithelial membrane antigen. *Indicates rare or no tumor cells to score on CMA.

$\dagger$ Indicates cases with agreement between the CMA and original sections.

used to construct the CMA. The proportion of tumor cells in the original block and the subsequent cores on CMA were similar (ranging from $5 \%$ to $90 \%$, Fig. 1 and Table 2). In the majority of cases, although tumor cells were found in all cases when counting all 3 cores, 1 or 2 cores did not have tumor cells in 4 cases that had a low tumor-cell burden $(\leq 10 \%)$ in the original cell block (Fig. 1, top left core with no cells). To determine the potential usefulness of using CMA for multiple marker testing, tumor cell composition at a deeper section of CMA (Section 45) was compared with the original section and the first section of CMA. At deeper Section 45, all cases except 1 (This case was exhausted by Section 30.) had at least 2 cores, and 19 cases still had all 3 cores present, all having a percentage of tumor cells similar to that of the original cell block sections (Table 2).

AE1/AE3 antibody stained all 23 cases (Fig. 1, bottom 2 rows) on core biopsy (CB) (Fig. 2A') and CMA stained 21 strongly and 2 moderately (Fig. 2A, and Table 3 ). EMA antibody stained 21 cases strongly or moderately (Table 3 , Fig. $2 \mathrm{~B}$ and $\mathrm{B}^{\prime}$ ) while the other 2 cases had only rare tumor cells on the core to compare with the original cell block section and thus were not included. Immunostains of AE1/AE3 and EMA were mostly strongly positive (rare cases moderately positive) in CMA and showed $100 \%$ concordance between the originals and their corresponding cores on CMA regarding intensity and high percentage of positive tumor cells (Table 3). Ki-67 antibody stained 16 cases similarly between the original block section and CMA (11 cases strong, 3 cases moderate, and 2 cases weak; Fig. 2C and $\mathrm{C}^{\prime}$ ), while 3 cases scored differently. Four cases with no tumor cells present or with rare tumor cells were not stained for scoring (Table 3). Therefore, Ki-67 antibody showed somewhat lower concordance (84\%, 16 of 19 cases). Excluded were the 4 cases where there was either low tumor burden because the tumor cells were less than $10 \%$ in original sections and there were no tumor cells in CMA, or because only rare tumor cells were present but not stained in CMA.

Similarly, although CK7, CK20, ER, PR, TTF-1, and WT-1 were only tested for selected cases, they stained both original sections (Fig. 2D-I) and CMA (Fig. 2D $-\mathrm{I}^{\prime}$ ) with a high level of agreement (Table 4). The tumor cells stained from negative (less than $5 \%$ tumor cell stained) to positive (more than 5\% and up to $100 \%$ tumor cells stained), and the overall staining pattern (cytoplasmic for CK7, CK20, or nuclear for ER, PR, TTF-1, and WT-1) and intensity of the original blocks were recapitulated by CMA cores.

\section{DISCUSSION}

TMA allows more rapid validation of multiple immunohistochemical markers than the conventional individual case-based method. ${ }^{2}$ There have been reports using bone marrow biopsy material, fine-needle aspiration, and cell block material for array construction, ${ }^{9-11}$ but multiple marker validation study using CMA from effusions has not been performed. ${ }^{9}$ This study used 3 cores, each $0.6 \mathrm{~mm}$ in diameter, from effusion cell blocks of different primary tumors to construct a CMA. It showed that CMA was representative of the original cell blocks with tumor cell composition at deeper sections (to Section 45), and that immunostaining pattern, intensity, and percentage were similar to that of the original section for antibodies tested. Concordance was high, from $84 \%$ for Ki67 to $100 \%$ for AE1/AE3 and EMA. There were rare cases where low tumor burden in the original block coupled with low percentage of staining by an antibody (mostly noticeable in Ki-67 staining) resulted in slightly lower concordance. In this study, CMA was constructed from cell blocks made by methods similar to surgical pathology specimens (fixation with $10 \%$ buffered formalin solution). However, for cytological specimens which have been processed differently (fixation by alcohol or methanol), additional testing is needed before accepting CMA as a routine marker testing tool because it is known that other fixations might not be optimal for detection of some 
TABLE 4

High Concordance Between CMA and Original Cell Block on Other Antibodies Applied to Selected Samples

\begin{tabular}{|c|c|c|c|c|c|c|c|c|c|c|c|c|}
\hline \multirow{4}{*}{$\begin{array}{l}\text { On CMA } \\
\text { Sections }\end{array}$} & \multicolumn{12}{|c|}{ No. of Cases Stained Positive or Negative } \\
\hline & \multicolumn{12}{|c|}{ 0n Original Cell Block Sections } \\
\hline & \multicolumn{2}{|c|}{ CK7 } & \multicolumn{2}{|c|}{ CK20 } & \multicolumn{2}{|c|}{ ER } & \multicolumn{2}{|c|}{ PR } & \multicolumn{2}{|c|}{ WT-1 } & \multicolumn{2}{|c|}{ TTF-1 } \\
\hline & Negative & Positive & Negative & Positive & Negative & Positive & Negative & Positive & Negative & Positive & Negative & Positive \\
\hline \multicolumn{13}{|l|}{ Breast (5) } \\
\hline Negative & - & - & 5 & - & 2 & - & 3 & - & $\mathrm{n} / \mathrm{a}$ & $\mathrm{n} / \mathrm{a}$ & $\mathrm{n} / \mathrm{a}$ & $\mathrm{n} / \mathrm{a}$ \\
\hline Positive & - & 5 & - & - & - & 3 & - & 2 & $\mathrm{n} / \mathrm{a}$ & $\mathrm{n} / \mathrm{a}$ & $\mathrm{n} / \mathrm{a}$ & $\mathrm{n} / \mathrm{a}$ \\
\hline \multicolumn{13}{|l|}{ Lung (5) } \\
\hline Negative & - & - & 5 & - & $\mathrm{n} / \mathrm{a}$ & $\mathrm{n} / \mathrm{a}$ & $\mathrm{n} / \mathrm{a}$ & $\mathrm{n} / \mathrm{a}$ & $\mathrm{n} / \mathrm{a}$ & $\mathrm{n} / \mathrm{a}$ & 1 & - \\
\hline Positive & - & 5 & - & - & $\mathrm{n} / \mathrm{a}$ & $\mathrm{n} / \mathrm{a}$ & $\mathrm{n} / \mathrm{a}$ & $\mathrm{n} / \mathrm{a}$ & $\mathrm{n} / \mathrm{a}$ & $\mathrm{n} / \mathrm{a}$ & - & 4 \\
\hline \multicolumn{13}{|l|}{ Ovary (8) } \\
\hline Negative & $\mathrm{n} / \mathrm{a}$ & $\mathrm{n} / \mathrm{a}$ & $\mathrm{n} / \mathrm{a}$ & $\mathrm{n} / \mathrm{a}$ & $\mathrm{n} / \mathrm{a}$ & $\mathrm{n} / \mathrm{a}$ & $\mathrm{n} / \mathrm{a}$ & $\mathrm{n} / \mathrm{a}$ & 1 & - & $\mathrm{n} / \mathrm{a}$ & $\mathrm{n} / \mathrm{a}$ \\
\hline Positive & $\mathrm{n} / \mathrm{a}$ & $\mathrm{n} / \mathrm{a}$ & $\mathrm{n} / \mathrm{a}$ & $\mathrm{n} / \mathrm{a}$ & $\mathrm{n} / \mathrm{a}$ & $\mathrm{n} / \mathrm{a}$ & $\mathrm{n} / \mathrm{a}$ & $\mathrm{n} / \mathrm{a}$ & - & 7 & $\mathrm{n} / \mathrm{a}$ & $\mathrm{n} / \mathrm{a}$ \\
\hline \multicolumn{13}{|l|}{ GI (5) } \\
\hline Negative & 1 & $1^{*}$ & 5 & - & $\mathrm{n} / \mathrm{a}$ & $\mathrm{n} / \mathrm{a}$ & $\mathrm{n} / \mathrm{a}$ & $\mathrm{n} / \mathrm{a}$ & $\mathrm{n} / \mathrm{a}$ & $\mathrm{n} / \mathrm{a}$ & $\mathrm{n} / \mathrm{a}$ & $\mathrm{n} / \mathrm{a}$ \\
\hline Positive & - & 3 & - & - & $\mathrm{n} / \mathrm{a}$ & $\mathrm{n} / \mathrm{a}$ & $\mathrm{n} / \mathrm{a}$ & $\mathrm{n} / \mathrm{a}$ & $\mathrm{n} / \mathrm{a}$ & $\mathrm{n} / \mathrm{a}$ & $\mathrm{n} / \mathrm{a}$ & $\mathrm{n} / \mathrm{a}$ \\
\hline
\end{tabular}

$\mathrm{n} / \mathrm{a}$ indicates not stained for the antibody.

*Indicates the low or no tumor cells to score on CMA.

markers, such as ER and PR. ${ }^{12,13}$ In the authors' experience, however, different thrombin clot cell block methods (fixation in $10 \%$ formalin) with or without specimens first being fixed in a methanol-based fixative such as CytoLyt (Cytyc Corporation, Malborough, Mass) have similar immunostain profiles in several markers tested, including ER and PR (C.W. Michael, unpublished data).

In this study, the 3 cores in CMA were representative of the original $\mathrm{CB}$ in the majority of cases. Only in rare instances did all 3 cores have no tumor cells or low tumor cells that were not stained for purpose of scoring. The necessity of using multiple cores in TMA has been demonstrated in reducing the nonconcordance rate. In one study, nonconcordance rate was $9.4 \%$ for single core, $4.4 \%$ for 2 cores, and $3.7 \%$ for 3 cores. $^{2}$ In some reports, single-core TMA has been shown to have rather satisfactory reliability (95\%-98\% concordance with whole tissue section) in detecting protein expression and gene amplification in breast cancer. ${ }^{3,14}$ Because cell blocks from effusions and other cytological samples tend to have smaller tissue fragments or cell clusters than a histological sample, a loss of 1 to 3 cores in rare cases and no tumor cells in 1 of the 3 cores in the deeper section in a few others was observed, arguing for using 3 cores in constructing a CMA to increase its representation of the original material.

In addition, although only 9 commonly used antibodies were tested, the estimated cost associated with constructing the CMA and staining 9 CMA slides is less than $\$ 1000$, with the majority of the cost incurred in constructing CMA (from $\$ 400$ to $\$ 800$ depending on the type of array and institution), while the cost of staining with 9 antibodies is much less $(\leq \$ 250$; approximately $\$ 25$ per stain $\times 9)$. It translated into a saving of more than $50 \%$ when compared with the cost of testing all 9 antibodies on original cell block sections $(\geq \$ 2500, \$ 25 \times$ approximately 120 sections). Additional marker testing using this CMA would lead to more cost savings in research or clinical operations.

In conclusion, although a pilot study, it is demonstrated here for the first time that CMA is a reliable method for validating immunocytochemical markers in research or clinical laboratories. CMA can represent the original cell block material accurately in tumor cell composition and in testing of commonly used antibodies in staining of cytoplasm, membrane, and nuclei. Therefore, it could be easily deployed in either research or clinical laboratories for a rapid marker validation. Although the initial construction of CMA is neither simple nor inexpensive, the potential for high-volume testing makes it cost efficient despite the initial costs associated with a CMA construction.

\section{REFERENCES}

1. Schneider V. Tissue microarrays for testing molecular biomarkers of cervical intraepithelial neoplasia: feasibility study. Acta Cytol. 2006;50:123-128. 
2. Hoos A, Urist MJ, Stojadinovic A, et al. Validation of tissue microarrays for immunohistochemical profiling of cancer specimens using the example of human fibroblastic tumors. Am J Pathol. 2001;158:1245-1251.

3. Zhang D, Salto-Tellez M, Putti TC, Do E, Koay ES. Reliability of tissue microarrays in detecting protein expression and gene amplification in breast cancer. Mod Pathol. 2003;16:79-84.

4. Leversha MA, Fielding P, Watson S, Gosney JR, Field JK. Expression of p53, pRB, and p16 in lung tumours: a validation study on tissue microarrays. J Pathol. 2003;200:610619.

5. Su Y, Shrubsole MJ, Ness RM, et al. Immunohistochemical expressions of Ki-67, cyclin D1, beta-catenin, cyclooxygenase-2, and epidermal growth factor receptor in human colorectal adenoma: a validation study of tissue microarrays. Cancer Epidemiol Biomarkers Prev. 2006;15:1719-1726.

6. Waterworth A, Hanby A, Speirs V. A novel cell array technique for high-throughput, cell-based analysis. In Vitro Cell Dev Biol Anim. 2005;41:185-187.

7. Fons G, Burger MP, Ten Kate FJ, van der Velden J. Identification of potential prognostic markers for vulvar cancer using immunohistochemical staining of tissue microarrays. Int J Gynecol Pathol. 2007;26:188-193.

8. Gomaa W, Ke Y, Fujii H, Helliwell T. Tissue microarray of head and neck squamous carcinoma: validation of the methodology for the study of cutaneous fatty acid-binding protein, vascular endothelial growth factor, involucrin and Ki-67. Virchows Arch. 2005;447:701-709.

9. Wen $\mathrm{CH}, \mathrm{Su}$ YC, Wang SL, Yang SF, Chai CY. Application of the microarray technique to cell blocks. Acta Cytol. 2007; 51:42-46.

10. Zimpfer A, Schonberg S, Lugli A, et al. Construction and validation of a bone marrow tissue microarray. J Clin Pathol. 2007;60:57-61.

11. Datta MW, Kahler A, Macias V, Brodzeller T, Kajdacsy-Balla A. A simple inexpensive method for the production of tissue microarrays from needle biopsy specimens: examples with prostate cancer. Appl Immunohistochem Mol Morphol. 2005;13:96-103.

12. Hudock JA, Hanau CA, Christen R, Bibbo M. Expression of estrogen and progesterone receptors in cytologic specimens using various fixatives. Diagn Cytopathol. 1996;15: 78-83.

13. Gong Y, Symmans WF, Krishnamurthy S, Patel S, Sneige N. Optimal fixation conditions for immunocytochemical analysis of estrogen receptor in cytologic specimens of breast carcinoma. Cancer. 2004;102:34-40.

14. Selvarajan S, Tan SY, Sii LH, Tan PH. c-erbB-2 (HER-2/neu) immunohistochemistry in invasive breast cancer: is there concordance between standard sections and tissue microarrays? Pathology. 2006;38:316-320. 